\title{
TECNOLOGIAS LIMPAS APLICADAS A GESTÃO DOS RESÍDUOS DO COCO
}

\author{
Carlos Enrique de M. Jerônimo \\ Doutorado em Engenharia Ambiental pela UFRN. Mestre em Engenharia \\ Química. Engenheiro Especialista em Processamento de Petróleo pela UERJ e \\ Engenheiro de Processamento da Petrobrás. Engenheiro Químico pela UFRN. \\ Endereço: R. Prof. Gerson Dumaresq, 259, Capim Macio, Natal - RN. E-mail: \\ c_enrique@hotmail.com
}

\begin{abstract}
RESUMO - Uma grande faixa da Zona da Mata do nordeste brasileiro vem apresentando, nos últimos tempos, um considerável desenvolvimento econômico, propiciado pelo plantio e cultivo do coco. Em paralelo a gravidade causada pela atividade de plantio do coco, surge a necessidade de se encontrar um destino adequado para os resíduos gerados, pois, o mesmo é descartado como lixo, agravando ainda mais o problema da destinação final em lixões. Problema esse, que poderia ser transformado em oportunidade de negócios, passando a ser matéria-prima, gerando renda, ajudando na sobrevivência familiar das regiões produtoras. $\mathrm{O}$ presente trabalho tem como objetivo, a elaboração de uma proposta de um sistema integrado abrangendo aspectos ambientais, técnico-científicos e sociais de direcionamento do resíduo orgânico com fins econômicos. Pode-se observar que a gravidade, principalmente em termos do montante, é alta, no entanto as formas de minimização do problema são simples, principalmente por se tratar de um resíduo biodegradável, e composto de fibras naturais, reaproveitadas em diversos processos industriais. Observou-se que a problemática pode ser solucionada pelo empenho empresarial, social e governamental para implantação e adaptação do sistema integrado.
\end{abstract}

PALAVRAS-CHAVES: Coco, Fibra de Coco, Resíduos Sólidos e Reaproveitamento.

ABSTRACT - A wide range of Zona da Mata of northeastern Brazil has been showing in recent times, considerable economic development, made possible by planting and cultivation of coconut. In parallel the severity caused by the activity of planting the coconut, there is a need to find a suitable destination for the waste generated, therefore it is discarded as waste, further aggravating the problem of disposal in landfills. This problem, which could be turned into business opportunity, becoming the raw material, generating income, helping the survival of the family producing regions. The present work aims at developing a proposal for an integrated system covering environmental, technical, scientific and social direction of the organic waste for economic purposes. It can be observed that the severity, especially in terms of the amount is high, however the ways to minimize the problem are simple, mainly because it is a waste, biodegradable and composed of natural fibers reused in various industrial processes. It was observed that the problem can be solved by business engagement, social and government for the implementation and adaptation of the integrated system.

KEYWORDS: Coconut, Coconut Fiber, Solid Waste and Reuse 


\section{INTRODUÇÃO}

A cultura do coqueiro (Cocos nucífera $L$.) é cultivada em aproximadamente 90 países, sendo típica de clima tropical. Tem origem no Sudeste Asiático e os maiores produtores mundiais são: Filipinas, Indonésia e Índia.

No Brasil a cultura do coqueiro, variedade gigante, chegou possivelmente, na colonização portuguesa em 1553, oriunda da ilha de Cabo Verde, que por sua vez, foram originadas de plantações Indianas, introduzidas na África.

A produção anual nacional de coco é superior a sete mil toneladas, sendo que isto representa o uso de apenas uma pequena parcela total de 900 milhões de cocos anualmente cultivados no país (IBGE, 1996). Dessa forma tem-se uma quantidade muita elevada de cascas de coco, ainda tratadas como resíduo, sendo que na realidade constituem matéria-prima em potencial.

O coqueiro é uma das plantas mais úteis do mundo, conhecida como "a árvore da vida", ela tem um papel importante na vida das pessoas que habitam as regiões tropicais e, indiscutivelmente, tem tanta importância nos dias de hoje como em tempos passados.

Constitui-se na mais importante das culturas perenes possíveis de gerar um sistema auto-sustentável de exploração como provam vários países do continente asiático.

Este fornece não somente alimento, água e óleo de cozinha, mas também folhas para telhados de palha, fibras para cordas, tapetes e redes, casca que pode ser usada como utensílios e ornamentos, açúcar e álcool podem ser feitos da seiva de sua inflorescência e inúmeros outros produtos elaborados de partes da planta.

Da casca de coco são extraídas fibras de diferentes comprimentos que servem para a fabricação de: tapetes, colchões, acolchoados para automóveis, escovas, pincéis, cordas marítimas e cama de animais. As características e propriedades da fibra de coco podem ser observadas na Tabela 1.

Tabela 1: Características e propriedades da fibra de coco

\begin{tabular}{l|r|}
\hline COMPRIMENTO DA FIBRA & 15 a $33 \mathrm{~cm}$ \\
\hline DIÂMETRO DA FIBRA & 0,05 a $0,4 \mathrm{~cm}$ \\
\hline COR & Marrom-claro a escuro, marrom-avermelhado \\
\hline TOQUE & Duro, um toque áspero \\
\hline ALONGAMENTO DE RUPTURA & Muito alto \\
\hline RESISTENCIA & A seco: fibra técnica 8 a 20 Km, fio 8 a 12 Km. A \\
& úmido: 93\% da resist. Seca. \\
\hline DENSIDADE & Muito reduzida, porque a fibra tem grande espaço oco.
\end{tabular}

Fonte: Harries e Harries(1976)

Dentre algumas Vantagem das Fibras Vegetais, de uma forma genérica, destacam-se como principais:

Baixa densidade

Baixo consumo de energia

$>$ Baixo custo

$>$ Baixa abrasividade

$>$ Atoxicidade

$>$ Biodegradabilidade

Reciclabilidade 
$>$ Altas propriedades de resistência mecânica específica

$>$ No coqueiro, segundo Ferreira et al. (1994), praticamente tudo é utilizado: raiz, estipe, inflorescência, folhas, palmito e principalmente o fruto que, mediante uma transformação geralmente simples, gera diversos subprodutos ou derivados, que podem classificar-se em três grupos:

$>$ Os produtos utilizados para a alimentação mediante o aproveitamento da matéria albuminosa do fruto;

$>$ Os produtos fibrosos, utilizados em particular, pela indústria têxtil

$>$ Outros produtos diversos de menor importância.

Nos últimos tempos, uma grande faixa da Zona da Mata do nordeste brasileiro vem apresentando, um considerável desenvolvimento econômico, propiciado pelo plantio e cultivo do coco. Plantio este, que acarreta, o desmatamento de grandes áreas da vegetação predominantemente "mata atlântica", tendo como conseqüência uma série de impactos ambientais, que influenciam diretamente no nível de qualidade de vida dos habitantes das pequenas localidades circundantes a esta região.

Em paralelo, a gravidade causada pela atividade de plantio do coco, surge a necessidade de se encontrar um destino adequado para os resíduos gerados, pois, o mesmo é descartado como lixo, agravando ainda mais o problema da destinação final em lixões. Problema esse, que poderia ser transformado em oportunidade de negócios, passando a ser matéria-prima, gerando renda, ajudando na sobrevivência familiar e tendo como conseqüência uma ação de fomento ao desenvolvimento econômico para as famílias das regiões produtoras.

O presente trabalho tem como objetivo, a elaboração de uma proposta preliminar de um sistema integrado: ambiental, técnico, científico e social de direcionamento do resíduo orgânico com fins econômicos. E são apresentados os resultados referentes ao levantamento realizado no estado do Rio Grande do Norte, visando a identificação dos pontos críticos e principais de ação.

\section{METODOLOGIA}

Foram feitas incursões periódicas às fazendas produtoras de coco no interior do estado do Rio Grande do Norte (nordeste brasileiro), às indústrias de beneficiamento de leite de coco, coco desidratado, água de coco e a locais de grande comercialização destes produtos, como por exemplo, a orla marítima urbana.

Nestes locais foram aplicados questionários técnicos e realizadas entrevistas, com o intuito de se avaliar a situação quanto ao impacto gerado por essas atividades, e quanto às formas de reuso dos resíduos já adotadas por essas empresas.

\section{RESULTADOS E DISCUSSÕES}

Os resultados obtidos mostram que nas fazendas produtoras há geração de um grande montante de resíduos provenientes das folhas dos coqueiros, que são aproveitados como adubo no próprio plantio. No entanto, esse montante, apesar da forma usual de reaproveitamento ocupa uma área considerável, pois não há compactação do material. Nas Figuras 1 e 2 são mostradas algumas ilustrações onde podem ser visualizadas de forma mais objetiva essa questão: 


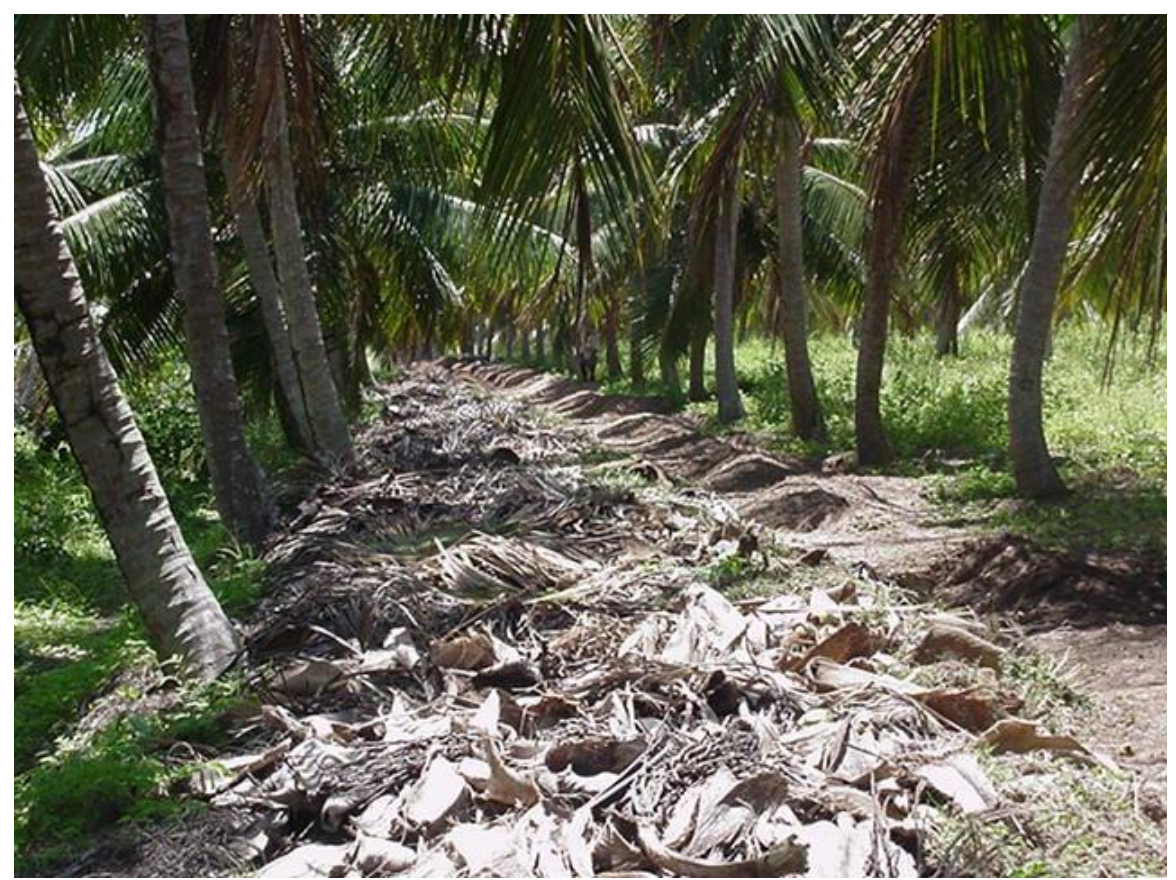

Figura 01: Utilização de Palhas de Coqueiros na Adubação destes.

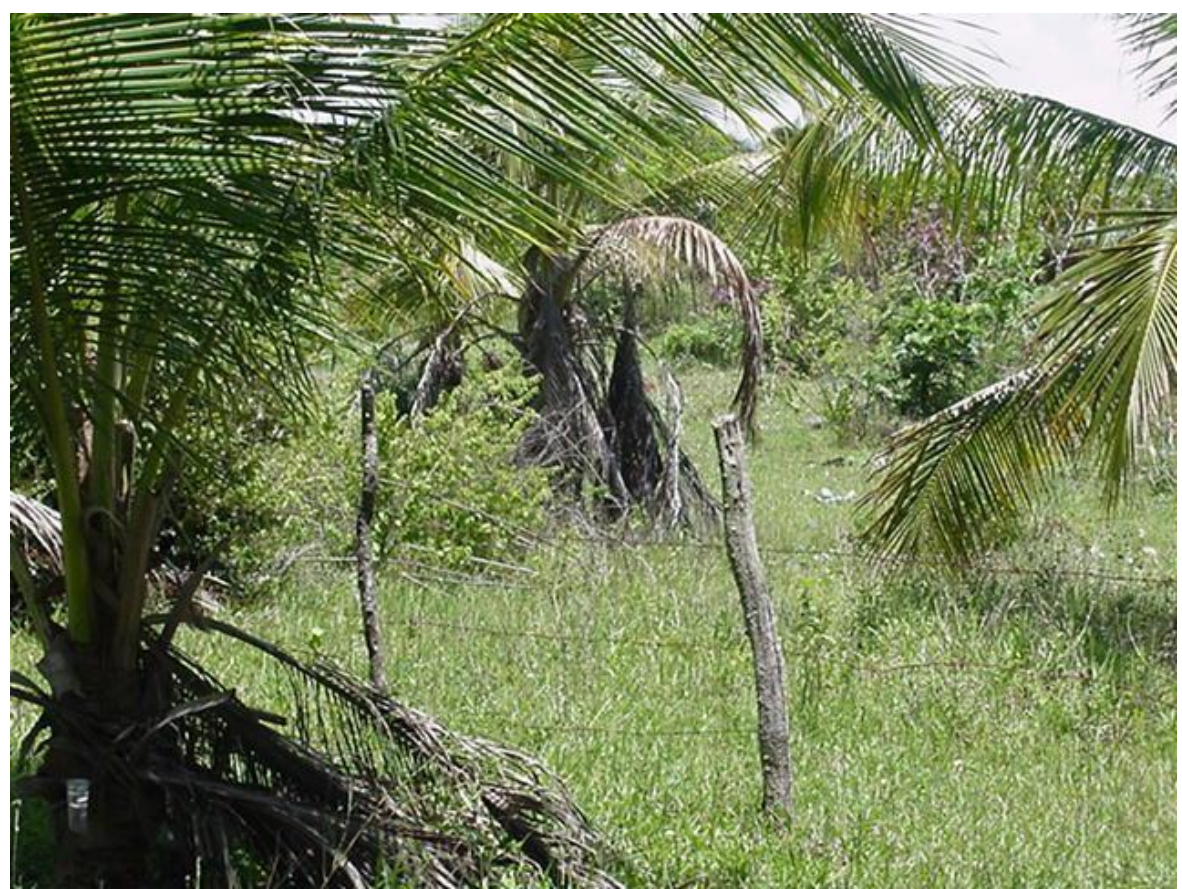

Figura 02: Amplitude de Abrangência das Copas do Coqueiro - Idéia do Montante Gerado.

No que diz respeito à geração de resíduos, na forma de cascas, foram identificadas formas diferenciadas em termos de intensidade de poluentes. Nas fazendas que comercializam o coco ainda em estado de maturação primário, ou seja, "verde", não ocorrem problemas com as cascas, no entanto as de coco seco, além das palhas apresentam tais materiais como resíduos. Os resíduos do coco verde são transferidos para os pólos de consumo, e serão abordados no decorrer do trabalho. 
As fibras provenientes dos frutos do coqueiro apresentam dificuldade em se degradar e acabam apodrecendo, prejudicando o solo, e/ou acumulando água, fato responsável pela disseminação de doenças epidêmicas, como é o caso do dengue. Observa-se, no entanto, que essas fibras têm diversas aplicações industriais, e é nesse ponto que se encontra a questão do reaproveitamento e da parametrização para projetos.

No que diz respeito às indústrias pesquisadas observou-se a geração de um montante de "quengas" do coco, que quando não são aproveitadas como combustíveis de caldeiras, acabam sendo dispostas para o sistema público de coleta. O que corresponde a um problema de sérias conseqüências, na medida que não existem aterros sanitários (encontra-se em fase de projeto) no estado do Rio Grande do Norte, além desses materiais apresentarem baixa compressibilidade.

Das etapas industriais, destaca-se também a produção de bagaços da polpa do coco, material de alto valor nutritivo, e que pode ser reaproveitado na produção de rações animais e extração de gorduras. Nesse trabalho, no entanto não será dado enfoque a esta questão. E sim, apenas aos resíduos fibrosos não comestíveis (principal elemento causador de impactos ambientais).

Nas praias urbanas, observou-se que a maior fração de lixo encontrada é de cocos verdes, principalmente, em virtude do peso específico bastante elevado que este material apresenta, quando comparado aos demais resíduos praianos. No entanto, não foi detectado nenhum sistema de triagem para estes resíduos, ao contrário, foi observado que em quase todas as praias pesquisadas ocorre a disposição inconsciente e prejudicial, destes materiais, ao longo da costa e no próprio oceano.

Com base nos resultados obtidos, pesquisou-se na literatura específica e em exemplos de casos industriais, meios para o reaproveitamento dos resíduos, fato este que permitiu a criação de uma proposta preliminar de um sistema integrado para o reaproveitamento destes materiais, mostrado na Figura 03. De antemão, podemos destacar as principais formas encontradas e que se mostraram economicamente e socialmente viáveis em outras regiões do país:

Confecção de Utensílios para Cultivo de Mudas e Plantas Ornamentais.

$\square$ Extração das Fibras para Reuso como preenchimento de estofamentos, em substituição as poliuretanas.

- Produção de Carvão Ativado (a partir de processo de incineração);

$\square$ Uso como piso, em criatórios de animais.

- Utensílios Secundários: Pincéis, Tapetes etc. 


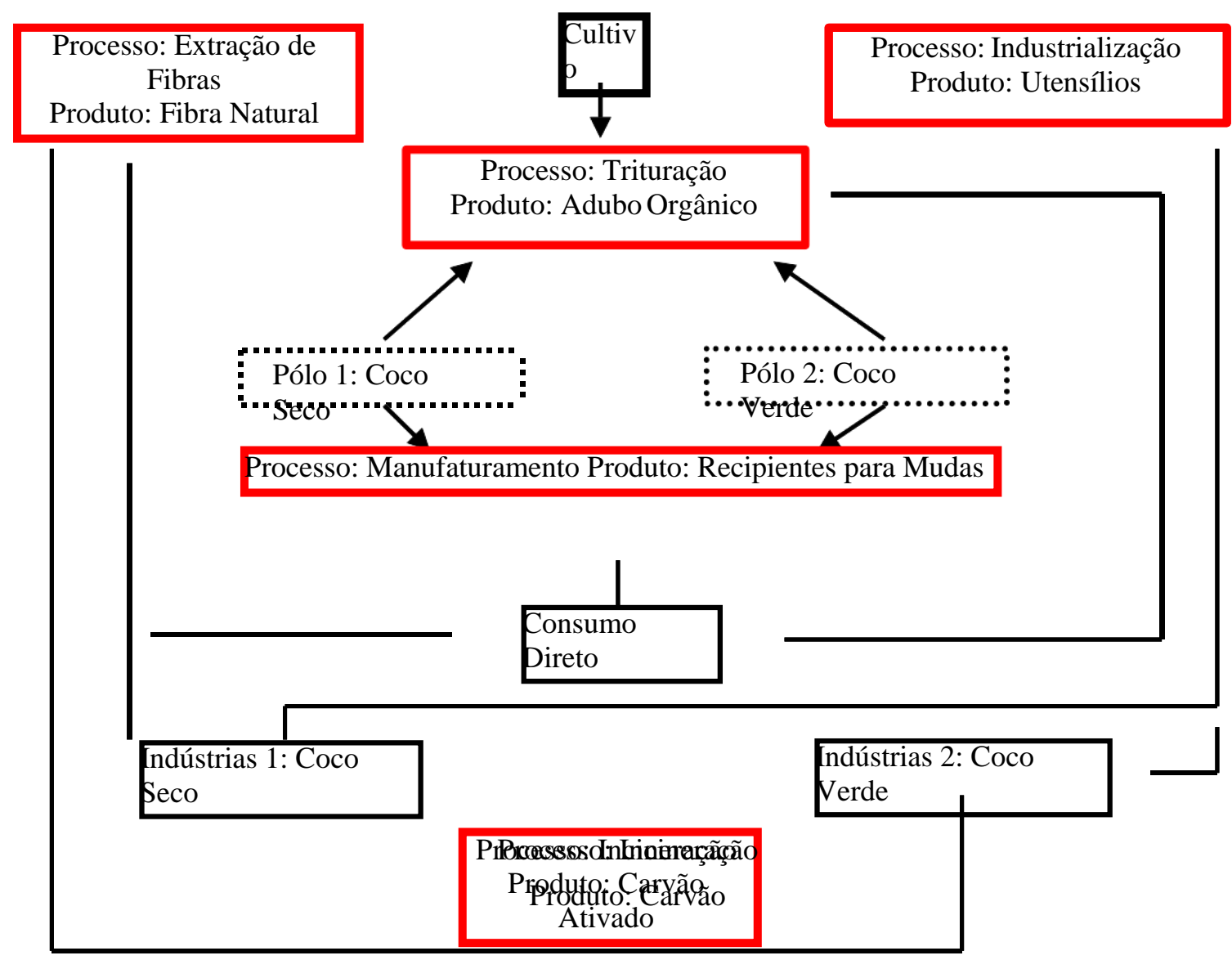

\section{Figura 03: Modelo Proposto para Reaproveitamento de Resíduos da Parte Não Comestível do Coco.}

Destacados os principais itens possíveis de inclusão, ponderou-se a viabilidade técnica, a agregação de valor e regressão de volume observada, tendo os pesos observados nas Tabelas 02, 03, 04 e 05 .

Tabela 2: Dificuldade Técnica de Implantação, Consideração pelo Número de Processos Envolvidos.

\begin{tabular}{|c|c|c|}
\hline ATIVIDADE & PESO TECNICO & DESCRIÇÃO \\
\hline Extração de Fibras & 4 & $\begin{array}{c}\text { Processo que requer alto consumo energético } \\
\text { para secagem, amplas áreas de estoque, } \\
\text { tratamento químico para retardo do } \\
\text { envelhecimento e especialização de pessoal. }\end{array}$ \\
\hline Industrialização & 3 & $\begin{array}{c}\text { Necessita de outros produtos para produção } \\
\text { do material final. Independe unicamente do } \\
\text { ramo em questão. }\end{array}$ \\
\hline Trituração & 10 & $\begin{array}{c}\text { Etapa única de processo. Apresenta um } \\
\text { consumo alto de energia, o que representa } \\
\text { o }\end{array}$ \\
\hline Manufaturamento & 12 & $\begin{array}{c}\text { Atividade que não processo. } \\
\text { profissional, e intuitivamente já é pacte parte } \\
\text { das }\end{array}$ \\
\hline
\end{tabular}




\begin{tabular}{|l|l|l|}
\hline & & \multicolumn{1}{|c|}{ atividades da cultura. } \\
\hline Incineração & 7 & $\begin{array}{l}\text { Alto consumo energético, no entanto, } \\
\text { necessita de etapas secundárias, de ordem } \\
\text { química ao processo. }\end{array}$ \\
\hline
\end{tabular}

Tabela 3: Agregação de Valor ao Produto.

\begin{tabular}{|c|c|l|}
\hline ATIVIDADE & $\begin{array}{c}\text { VALOR } \\
\text { AGREGADO }\end{array}$ & \multicolumn{1}{c|}{ DESCRIÇÃo } \\
\hline Extração de Fibras & 10 & $\begin{array}{l}\text { O material torna-se utilizável em substituição } \\
\text { a poliuretanas, com isso, seu uso é presente } \\
\text { em instrumentos de alto valor agregado. Boa } \\
\text { aceitação no mercado. }\end{array}$ \\
\hline Industrialização & 7 & $\begin{array}{l}\text { Produtos de alto valor, no entanto, não são } \\
\text { agregados unicamente pelo resíduo. }\end{array}$ \\
\hline Trituração & 4 & $\begin{array}{l}\text { Por ser um processo simples, concentra } \\
\text { grande montante em grandes quantidades com } \\
\text { alta eficiência, tornando o produto de alta } \\
\text { aceitação e ampla aplicação. }\end{array}$ \\
\hline Manufaturamento & 2 & $\begin{array}{l}\text { Produto que não tem um consumo essencial, } \\
\text { sendo muitas vezes, requisitado em áreas } \\
\text { nobres, e em casos das mudas não agregam } \\
\text { valores consideráveis. }\end{array}$ \\
\hline Incineração & 10 & $\begin{array}{l}\text { Produto de Alto Consumo na Indústria } \\
\text { Química (carvão ativado) }\end{array}$ \\
\hline
\end{tabular}

Tabela 4: Avaliação Econômica: Ponderação pelo Custo/Benefício

\begin{tabular}{|c|c|l|}
\hline ATIVIDADE & $\begin{array}{c}\text { PESO } \\
\text { ECONÔMICO }\end{array}$ & \multicolumn{1}{c|}{ DESCRIÇÃo } \\
\hline Extração de Fibras & 5 & $\begin{array}{l}\text { Alto Custo de produção. Boa aceitação no } \\
\text { Mercado, apresentando valores comerciais } \\
\text { consideráveis. }\end{array}$ \\
\hline Industrialização & 4 & $\begin{array}{l}\text { Alto Custo com materiais adicionais ao } \\
\text { processo. Taxa de retorno, considerando o } \\
\text { resíduo, mediano. }\end{array}$ \\
\hline Trituração & 7 & $\begin{array}{l}\text { Processo Simples a baixo custo. Aumento } \\
\text { considerável no preço, partindo do valor nulo. }\end{array}$ \\
\hline Manufaturamento & 4 & $\begin{array}{l}\text { Produto de Baixo Custo. Baixa Rotatividade } \\
\text { Comercial. }\end{array}$ \\
\hline Incineração & 5 & $\begin{array}{l}\text { Alto Custo de Processamento. Alto Preço } \\
\text { Comercial. }\end{array}$ \\
\hline
\end{tabular}

Tabela 5: Redução de Volume. 


\begin{tabular}{|c|c|l|}
\hline Extração de Fibras & 2 & $\begin{array}{l}\text { Nesse processo ocorre apenas o o } \\
\text { desfibramento, sendo a redução feita } \\
\text { basicamente pela exclusão de partes } \\
\text { impróprias. }\end{array}$ \\
\hline Industrialização & 2 & $\begin{array}{l}\text { O Montante considerado é baixo, já que } \\
\text { requer o uso de outras matérias-primas. }\end{array}$ \\
\hline Trituração & 7 & $\begin{array}{l}\text { Processo altamente eficiente, pois transforma } \\
\text { as cascas em finos. No entanto, mantém a } \\
\text { umidade. }\end{array}$ \\
\hline Manufaturamento & 2 & $\begin{array}{l}\text { A redução é basicamente pela exclusão de } \\
\text { partes impróprias. }\end{array}$ \\
\hline Incineração & 10 & $\begin{array}{l}\text { Exclusão da água e matéria orgânica, } \\
\text { reduzindo a níveis altamente eficientes. }\end{array}$ \\
\hline
\end{tabular}

No que diz respeito a abrangência em termos sociais e ambientais podemos destacar as seguintes relações:

Extração de Fibras: Aproveitamento de mão-de-obra especializada dos centros urbanos. E geração de resíduos secundários, não eliminando por completo o problema, e sim apenas transferindo.

口 Industrialização: Aproveitamento de mão-de-obra especializada dos centros urbanos. Pouca utilização de resíduos, baixa ação no controle ambiental.

- Trituração: Uso dos próprios produtores na elaboração dos produtos. Geração de renda para as atividades primárias. Boa ação ambiental, a medida que no uso desse material, adubação, se tem a completa degradação do material.

\ Manufaturamento: Mão-de-obra pouco qualificada, com geração de receita para as áreas primárias. Baixa ação como tratamento de resíduos.

口 Incineração: Profissionais qualificados. Geração de empregos no setor secundário. Alta eficiência ambiental, requisitando controles de poluentes gasosos, para não ocorrer danos ambientais.

Contudo, o gerenciamento de locais de uso e implantação combinada desses processos requer um estudo econômico minucioso, que será realizado em etapas seguintes da elaboração desse projeto. Entretanto, os pesos obtidos e discutidos nesse trabalho serão a fundamentação na análise custo-benefício da implementação do sistema integrado proposto.

\section{CONCLUSÕES}

Pode-se concluir que a gravidade, principalmente em termos do montante, é alta, no entanto as formas de minimização do problema são simples, principalmente por se tratar de um resíduo biodegradável, e composto de fibras naturais, reaproveitadas em diversos processos industriais. Observa-se que a problemática pode ser solucionada pelo empenho empresarial, social e governamental para implantação e adaptação do sistema integrado.

\section{REFERÊNCIAS BIBLIOGRÁFICAS}

CARIOCA JDB. et al. Biomassa: Fundamentos, Aplicações, BNB, UFC, 1982. Coe lho JC.

Biomas sa, Biocombus t í v e i s, Bioenergia, Brasília, 1982. 
CASTOR J.P.A. Modelos para Aproveitamento Técnico-Econômico do Endocarpo do Coco da Baía. Dissertação de Doutorado, USP, São Paulo/SP, 1985.Steele PE. Coconut Industries Development and the Importance of Technical Innovation. Workshop on Wet Processing of Coir, Alleppey. December 1997, 29 - 37, 1997.

EMBRAPA. Centro de pesquisa Agropecuária dos Tabuleiros Costeiros, Aracaju - SE. Recomendacão técnicas para o cultivo do coqueiro. Aracaju, 1993, 44p. (Circular Técnica $\left.\mathrm{n}^{\mathrm{o}} 1\right)$.

FERREIRA, J.M.S.; WARWICK, D.R.N.; SIQUEIRA, L.A . Cultura do coqueiro no Brasil. Aracaju: EMBRAPA-SPI, 1994, 309p.

INSTITUTO BRASILEIRO DE GEOGRAFIA E ESTATÍSTICA. $\underline{\text { Anuário Estatístico do }}$ Brasil, seção 3, p.33,1996.

PA N N I R S E L V AM P .V. Comput e r Aided and Economic Analyseis of Integraded Microbial Pr o c e s s f o r F i b e r, Fe e d a n d Fe r t i 1 i z e r Production from Sisal Biomass Residuaes. SIENTEX2000 - I Simpósio Internacional de Engenharia Têxtil, Natal/RN, 2000.

VAN DAN J.E.G. Wet Processing of Coir: drying,bleaching, dyeing, softening and printing. FAO. Techinical Paper Nº December, 1999. 